\title{
Morphological Characteristics, Phenolic and Terpenoid Profiles in Garden Chrysanthemum Grown in Different Nutritional Conditions
}

\author{
Cristina C. MIRCEA (ARSENE) ${ }^{1}$, Oana CIOANCÅ², \\ Lucia DRAGHIA ${ }^{1}$, Monica HĂNCIANU ${ }^{2}$ \\ ${ }^{I}$ University of Agricultural Sciences and Veterinary Medicine "Ion Ionescu de la Brad" Iaşi, Faculty of Horticulture, Department of Floriculture, 3 Aleea M. Sadoveanu \\ Street,700490,Iaşi_Romania; cris_arsene@yahoo.com;lucia@uaiasi.ro \\ ${ }^{2}$ University of Medicine and Pharmacy "Gr. T. Popa” Iaşi, Faculty of Pharmacy, Department of Pharmacognosy, 16 Universității Street, 700115, Iaşi, Romania; \\ oana.cioanca@gmail.com (*orrespondingauthor);mhancianu@yahoo.com
}

\begin{abstract}
Chrysanthemum indicum L. (Dendranthema indicum (L.) Des Moul) became useful as herbs and curatives in different parts of the world. In the current study, the chemical profile of outdoor cultivated Chrysanthemum indicum 'Avalone Red' was investigated for polyphenolic acid derivatives, flavonoids, alantolactone and ursolic acid using thin layer chromatography (TLC). Total phenolic content was determined through a classical method and semiquantitative analyses of alantolactone were performed through the HPLC method. Morphological and yield parameters and the chemical profile of plants were registered in two different nutritional statuses (local and enriched soil conditions). The results indicate that the studied cultivar is a potent source of phenolics and that the fertilisation increases the plant biosynthetic capacity for polyphenols $(159.74 \mathrm{mg} / 100 \mathrm{~g}$ in leaves and $79.82 \mathrm{mg} / 100 \mathrm{~g}$ in flowers, in unfertilised plants, and $388.54 \mathrm{mg} / 100 \mathrm{~g}$ and $144.86 \mathrm{mg} / 100 \mathrm{~g}$ in leaves and flowers of fertilised plants, respectively, expressed as gallic acid equivalent value). The studied cultivar contains hyperoside (and other derivatives) and four main polyphenol carboxylic acids (including chlorogenic acid). Ursolic acid was not detected. The high pressure liquid chromatography (HPLC) analyses confirmed the presence of alantolactone identified in TLC chromatogram. Moreover, the fertilised plant samples contain only traces of alantolactone compared to the unfertilised plants. Alantolactone is present in a small amount (less than $0.1 \mathrm{mg} \%$ ) but its presence alerts to the potential allergenic effect of the plant. Besides their ornamental value, chrysanthemums can have a wide array of uses due to their high amounts of bioactive compounds.
\end{abstract}

Keywords: economic botany, nutrients, ornamental plants, secondary metabolites

\section{Introduction}

Chrysanthemum indicum L., syn. Dendranthema indicum (L.) Des Moul, belonging to the Asteraceae family, is an ornamental with a wide array of uses, from decorative (garden, pot or cut flowers), food (tea, condiments), cosmetics, insecticides to medicine in numerous cultures around the world (Huang and Ling, 1996; Wickens, 2001; Kumar et al., 2005; Cantor and Buta, 2010; Lim, 2014; Bessada et al., 2015). As plants became useful as herbs and curatives, their economic value increased as a valuable example of botanical versatility. Despite of its recognized medicinal properties in Asian countries, Chrysanthemum is considered a predominantly ornamental crop in Europe. In particular, very little is known about the evolution of biomass or flower productivity related to secondary metabolites contents. The branching patterns of crops and reduction of height are also an important component in controlling the yield and crop quality and would also provide economic advantages for growers (Zheng, 2001). From this point of view, economic interest could be focused on modern chrysantemum cultivars with a compact, spherical habit and superior branch flexibility.

Terpenoids and certain phenolic constituents are responsible for the value of many Asteraceae in pharmacology (Achika et. al., 2014). Antioxidant activity was highly correlated with phenolic and flavonoid contents (Gould and Lister, 2006; Lattanzio et al., 2008; Dai and Mumper, 2010; Wink, 2011; Petrussa et al., 2013). Asteraceae are triterpene accumulators. From this group, ursolic acid is a pentacyclic triterpenoid proved to be cardioprotective (Liobikas et al., 2011; Senthil et al., 2007). Sesquiterpenes are volatile components of the scent and fragrances of Asteraceae plants. Many have potential biological 
372

activities (Kumar et al., 2005; Li et al., 2009; Liang-Yu et al., 2010; Wang et al., 2010; Fraga, 2013).

Chrysanthemum indicum have a strong aroma and many of the previous researches focused on the essential oil of this plant (Kumar et al., 2005; Lawal et al., 2014). Chemistry indicates that C. indicum oil contains more than 63 volatile compounds which included eucalyptol, $\alpha$-pinene, $\alpha$-neoclovene, verbenone, chrysanthenone, camphor, chrysanthemine, sesquiterpenes, among others (Liang-Yu et al., 2010). At least ten flavonoids were identified, including quercetin, myricetin and luteolin-7glucoside. It suggests that the $C$. indicum flowers are a good source of natural quercetin and myricetin for the development of potential pharmaceuticals (Liang-Yu et al., 2010). Methanolbased extracts of flowers yielded flavones, flavone glycosides, sesquiterpenes (Yoshikawa et al., 1999; Kumar, 2005; Bi et al., 2010), and ethanol extracts of flowers yielded chlorogenic acid vanilinic acid, acacetin, linarin and other compounds (Debnath et al., 2013).

Alantolactone, eudesmanolid-type sesquiterpene lactones, have been found to have pharmacological actions including antiinflammatory, antimicrobial and anticancer properties (Chadwick et al., 2013; Rasul et al., 2013). On the other hand, methylated sesqui-terpenelactones are redoubtable allergens of Chrysanthemum genus (Stampf et al., 1982; Warshaw and Zug, 1996) and could induce allergic contact dermatitis (Tanaka et al., 1987; Lowell, 1993; Crosby, 2004; Swierczyńska-Machura et al., 2006). The offending allergen may be present in cultivated plants, botanical extract itself or another ingredient such as fragrance (Jack et al., 2013). The allergenic lactones generally are contained in trichomes that cover the stems, leaves or flowers of plants. Many plant species produce glandular trichomes that biosynthesize toxic substances such as terpenes, lactones, dermatotoxic quinones (Burzo and Toma, 2013). In the Asteraceae family, glandular trichomes are found along with other secretory structures, such as secretory channels (Niță et al., 2001). The evaluation of allergenic potential of these plants is a problem of occupational and public health.

The concentration of plant secondary metabolites was found to be influenced by environmental conditions such as light intensity, $\mathrm{CO}_{2}$ levels, temperature, fertilization, other soil and climatic conditions and agrotechniques applied (Buta et al., 2011; Habib and Zaghloul, 2012).

Phytochemical profiling studies are of interest for the purpose of detecting species with similar compounds profiles that may have a greater impact into usage of these raw materials as important resources for cosmetic and pharmaceutical industry (Filippini et al., 2010).

The present study aims to simultaneously investigate the alantolactone, ursolic acid, flavonoids and polyphenol-carboxilic acids in the aerial parts of Chrysanthemum indicum cv. 'Avalone Red'. Conventional yield and morphological parameters, qualitative profile of aforementioned secondary metabolites, semiquantitative evaluation of alantolactone and total polyphenolic content were evaluated. Microscopic morphological traits of flowers and leaves were analysed. The influence of fertilization on plant morphological traits was evaluated related to ornamental characteristics and to alantolactone and total polyphenolic content. The economic botanical importance of Chrysanthemum indicum cv. 'Avalon Red' is discussed related to studied metabolites and plant morphology.
Table 1. Physical properties of the experimental soil

\begin{tabular}{ccccc}
\hline Clay & Silt & Coarse sand & Fine sand & Texture \\
\hline $31.1 \%$ & $22.4 \%$ & $9.9 \%$ & $36.6 \%$ & Sandy-loam \\
\hline
\end{tabular}

\section{Materials and Methods}

Description of the study site

The research has been carried out in the 2014 cultivation year at the Floricultural Department of the University of Agricultural Sciences and Veterinary Medicine "Ion Ionescu de la Brad" Iaşi, Romania (4710'43”N and 27०37’14”E).

Evaluation of the physical (Table 1) and analytical properties of the top $250 \mathrm{~mm}$ of soil were determined just before planting. Analytical results indicated: $\mathrm{pH} 7.8$, humus content $4.2 \%, 3 \%$ carbonates, $29.5 \%$ cation exchange capacity, $1.08 \mathrm{me} / 100 \mathrm{~g}$ complex $\mathrm{Na}$. Values of elements registered were: $0.22 \%$ total N, $246 \mathrm{ppm}$ accessible $\mathrm{P}$ and $429 \mathrm{ppm}$ accessible $\mathrm{K}$. Zinc, copper, boron, mangan were $15 \mathrm{ppm}, 5.0 \mathrm{ppm}, 0.32 \mathrm{ppm}$ and $51 \mathrm{ppm}$ respectively.

Climatic data of the year 2014 emphasised normal temperature but higher rainfalls and humidity in the May-July interval and lower rainfalls and humidity in August-October in comparison with multiannual month averages. The average of the mean temperatures of the period between early May and the sampling date $\left(20^{\text {th }}\right.$ October) was $17.84 \pm 3.17^{\circ} \mathrm{C}$, while the average of the mean precipitations of the same period of time was $51.14 \pm 28.94 \mathrm{~mm}$.

\section{Experimentaldesign}

The experiment was performed as plot design based on randomised complete blocks with three replications. Chrysanthermum indicum 'Avalone Red' was studied related to biometric and yield parameters in two nutrient availabilities: local (V1) and enriched (V2) soil conditions. The chosen fertiliser was controlled-release with 5-6 months availability, NPK $(\mathrm{Mg})$ : 15-1012 (2), microelements B, Cu, Fe, Mn, Zn, supporting ornamental growth and development with easy maintenance. The fertiliser was administered just before planting, $75 \mathrm{~g} \mathrm{~m}^{-2}$. Rooted cuttings were planted in the field at the beginning of June, at a density rate of 4 plants $\mathrm{m}^{-2}$. Weeds were controlled manually. The plants were irrigated in correlation to the level of precipitation.

Measurement of concerned parameters was performed on the $20^{\text {th }}$ of October when plants reached maximum of decoration. The parameters followed were: height and width of plants, number of inflorescences per plant, diameter of inflorescences, total number of branches per plant, fresh and dry weight of plant, fresh and dry weight of inflorescences per plant (flower heads) and weight of 100 fresh inflorescences. Five plants were randomly selected from each plot to evaluate the morphological and yield parameters in both nutritional availabilities. Samples of aerial parts of the plants were used for analytical determinations.

\section{Plant material}

Cultivar 'Avalone Red' is a late flowering Chrysanthemum indicum, having compact, dome habit, 30-50 cm height and 40-50 $\mathrm{cm}$ width (Fig.1). Cultivation in full sun stimulates the development of highly branched plants, which results in a high display of flowers. Pinches are not required for most crops. The plants are easy to cultivate due to their hardiness.

Fresh aerial parts of cultivated plants were dried in a thermostatic oven at $35^{\circ} \mathrm{C}$ until three consecutive measurements were identical. The samples were codified as follows: F1/L1- 
inflorescences/leaves from unfertilized plants, F2/L2inflorescences/leaves from fertilized plants.

\section{Plant extract preparation}

Fragments $(2 \mathrm{~g})$ of dried leaves and inflorescences were extracted with methanol or acetonitrile $\mathrm{R}$ in the Laboratory of Pharmacognosy, Faculty of Pharmacy, University of Medicine and Pharmacy "Gr. T. Popa" Iaşi, Romania. For polyphenols identification and quantification, the methanolic extract was obtained $(1: 10, \mathrm{~m} / \mathrm{m})$ by repeated sonication for 15 minutes. The filtrates were dried to obtain concentrated extracts which were diluted in $1 \mathrm{~mL}$ methanol for thin layer chromatography (TLC). For terpenoids evaluation by TLC/HPLC, the test solutions were obtained in acetonitrile $\mathrm{R}(1,0 \mathrm{~g}$ powdered drug in $3 \mathrm{~mL}$ solvent, three times, sonicated for 15 minutes). The filtrates were reunited and brought to $10 \mathrm{~mL}$ in a volumetric flask. A quantum of 0.20 $\mu \mathrm{L}$ were used for HPLC analysis.

\section{Microscopic assessment}

A portion of the dried flowers (F1, F2) and separately parts of dried leaves and stems $(\mathrm{L} 1, \mathrm{~L} 2)$ were reduced to a powder, purplered for flowers respectively green for leaves, and examined under a microscope using chloral hydrate solution R. For each sample F1, F2, L1 and L2, microscopic plates were prepared with chloral hydrate. The plates were examined under an Optika microscope using 6x, 10x and 40x objectives. The common elements were photographed with a Canon 540 camera attached to the microscope.

Flavonoid and polyphenolic acid derivatives qualitative analyses

For a general description of the polyphenols pattern $12 \mu \mathrm{L}$ of a mixture of rutin, hyperoside and chlorogenic acid was applied on a silica gel $60 \mathrm{~F}_{254}$ pre-coated thin layer chromatography (TLC) plate. Chromatography solvents were: ethyl acetate-formic acidglacial acetic acid-water (100:11:11:25). After elution and air drying of the plate, natural product reagent was sprayed for detection and oven dried at $105^{\circ} \mathrm{C}$ for $5 \mathrm{~min}$. The characteristic spots were observed in UV light at $365 \mathrm{~nm}$.

\section{Totalphenolic content determination}

The total phenolic content of each sample was quantified with Folin-Ciocalteu reagent according to the Singleton and Rossi method (1965) using gallic acid as a standard. The measurements were performed on ABLE-JASCO V 550 UV-VIS spectrophotometer. The absorbance was measured at $765 \mathrm{~nm}$ versus blank samples. The blank consisted of samples, all reagents and solvents except sodium carbonate.

Terpenoids qualitativepattern evaluation by TLC

The elution systems in the present study were used as follows: a. For sesquiterpene lactones (alantolactones)

Standard compound: alantolactone, $12 \mu \mathrm{L}$

Solvents: hexane - ether $(25: 75, \mathrm{v} / \mathrm{v})$

Detection:Zimmermann reagent, VIS evaluation.

b. For triterpenes (ursolic acid)

Standard compounds: ursolic acid, oleanolic acid, $12 \mu \mathrm{L}$

Solvents: chlorophorm - glacial acetic acid - methanol - water $(60: 32: 12: 8, \mathrm{v} / \mathrm{v})$

Detection: anisaldehyde - sulphuric acid reagent, VIS evaluation.

In both tests, the TLC plates were sprayed with $10 \mathrm{~mL}$ of the reagent, heated at $100^{\circ} \mathrm{C}$ for $5 \mathrm{~min}$, then evaluated in VIS.

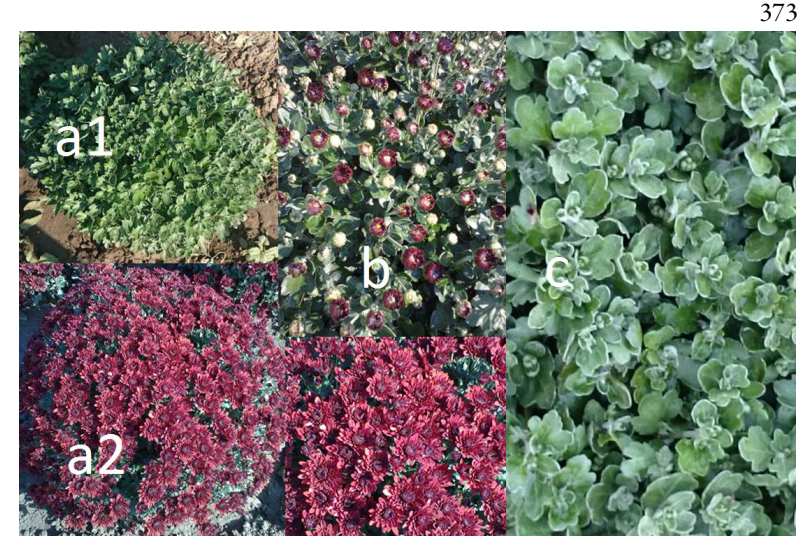

Fig. 1. Macroscopic characteristics: a - plant habit: a1 - vegetative stage; a2 - flowering stage; b - inflorescences (different stages); c - leaves (vegetative stage)

All solvents (acetonitrile, methanol, hexane, ethyl acetate, acetic acid, formic acid, chlorophorm) and standards (rutin, hyperoside, chlorogenic acid, alantolactone, ursolic acid) were HPLC grade.

\section{Semiquantitative alantolactone determination by HPLC}

A Thermo-Fischer UltiMate 3000 system coupled with DAD detector was used to assess the profile sesquiterpene lactones. The working conditions were: Accucore XL-C18 column ( 4.6 x 150 $\mathrm{mm}, 4 \mu \mathrm{m})$; column temperature: $34^{\circ} \mathrm{C}$; detection wavelength was set at $225 \mathrm{~nm}$ and the flow rate was $1.2 \mathrm{~mL} / \mathrm{min}$. The mobile phase consisting of two eluents as A (water) and B (methanol) used the following linear gradient elution: $0-3$ min $38 \%$ B; 3-20 $\min 45 \% \mathrm{~B} ; 20-30 \mathrm{~min} 45 \% \mathrm{~B} ; 30-55 \mathrm{~min} 55 \% \mathrm{~B}$; $55-57 \mathrm{~min}$ $100 \% \mathrm{~B} ; 70 \mathrm{~min} 100 \% \mathrm{~B} ; 90 \mathrm{~min} 38 \% \mathrm{~B}$. As standard, alantolactone was used in amount of $20 \mu \mathrm{L}$ of a $5 \mathrm{mg} / \mathrm{mL}$ solution. Five consecutive injections were done for repeatability purpose. Samples UV spectra registered at $225 \mathrm{~nm}$ were automatically compared by Chromeleon 7.2 software and the concentration was expressed as \% of the standard's aria/concentration.

\section{Statistical analyses}

All measurements and analyses were performed in triplicates. Statistical significance between mean values was assessed through classic statistical calculations: significance of differences between the variants using LSD tests (Ardelean et al., 2007). The variants were compared with their average. Data for quantitative and semiquantitative analytical determinations were presented as mean values \pm standard deviations.

\section{Results and Discussion}

\section{Morphological, ornamental and yield characteristics}

The macromorphology of studied Chrysanthemum indicum is shown in Fig. 1.

Cultural operations as "pinching" are time consuming and expensive. Studied cultivar requires neither "pinching" nor "staking" as mentioned by the breeders. These traits emphasised economic and ornamental advantages in landscaping and horticulture industry.

Management of plant nutrition enhances profitability through increased ornamental and yield parameters. Nutrient management is closely associated with fertilizer type, application rate, time and 
374

Table 2. Influence of fertilisation on morphological parameters

\begin{tabular}{lccccccc}
\hline Treatment & $\begin{array}{c}\text { Plant height } \\
(\mathrm{cm})\end{array}$ & $\begin{array}{c}\text { Plant width } \\
(\mathrm{cm})\end{array}$ & $\begin{array}{c}\text { Number of } \\
\text { inflorescences } \\
\text { per plant }\end{array}$ & $\begin{array}{c}\text { Number of ray- } \\
\text { florets per } \\
\text { inflorescence }\end{array}$ & $\begin{array}{c}\text { Number of disk- } \\
\text { florets per } \\
\text { inflorescence }\end{array}$ & $\begin{array}{c}\text { Diameter of } \\
\text { inflorescences } \\
(\mathrm{cm})\end{array}$ & $\begin{array}{c}\text { Total number of } \\
\text { branches per plant }\end{array}$ \\
\hline V1 & $29.50^{\mathrm{ns}}$ & $53.81^{\mathrm{ns}}$ & $674.00^{\circ 0}$ & $137.00^{\mathrm{ns}}$ & $92.00^{\circ}$ & $4.83^{\mathrm{xx}}$ & $362.50^{\text {ooo }}$ \\
V2 & $30.00^{\mathrm{ns}}$ & $54.03^{\mathrm{ns}}$ & $798.00^{\mathrm{xx}}$ & $140.00^{\mathrm{ns}}$ & $103.00^{\mathrm{x}}$ & $4.35^{\circ 0}$ & $483.700^{\mathrm{xxx}}$ \\
Average & 29.75 & 53.92 & 736.00 & 138.50 & 97.50 & 4.49 & 423.10 \\
LSD 5\% & 1.08 & 0.92 & 25.92 & 2.48 & 2.48 & 0.09 & 2.89 \\
LSD 1\% & 2.50 & 2.11 & 59.86 & 5.73 & 5.73 & 0.20 & 6.67 \\
\hline LSD 0.1\% & 7.95 & 6.73 & 190.48 & 18.24 & 18.24 & 0.63 & 21.22 \\
\hline Note: o/x= significant negative/positive differences; oo/xx=distinctly significant negative/positive differences; ooo/xxx= very significant positive/negative differences;
\end{tabular}

Note: $\mathrm{o} / \mathrm{x}=$ significant negative/positive differences; $\mathrm{oo} / \mathrm{xx}=$ distinctly significant negative/positive differences; $\mathrm{ooo} / \mathrm{xxx}=$ very significant positive/negative differences; ns=not significant

Table 3. Influence of fertilisation on yield parameters

\begin{tabular}{lccccc}
\hline Treatment & Fresh weight of plant $(\mathrm{g})$ & Dry weight of plant $(\mathrm{g})$ & $\begin{array}{c}\text { Fresh weight of } \\
\text { inflorescences per plant }(\mathrm{g})\end{array}$ & $\begin{array}{c}\text { Dry weight of inflorescences } \\
\text { per plant }(\mathrm{g})\end{array}$ & $\begin{array}{c}\text { Weight of 100 fresh } \\
\text { inflorescences }(\mathrm{g})\end{array}$ \\
\hline V1 & $1,100.00^{\circ 0}$ & $412.61^{\circ 0}$ & $691.13^{\mathrm{ns}}$ & $214.25^{\mathrm{ns}}$ & $102.74^{\mathrm{ns}}$ \\
V2 & $1,570.00^{\mathrm{xx}}$ & $590.47^{\mathrm{xx}}$ & $724.98^{\mathrm{ns}}$ & $224.63^{\mathrm{ns}}$ & $90.85^{\mathrm{ns}}$ \\
Average & $1,335.00$ & 501.54 & 708.05 & 219.44 & 96.79 \\
LSD 5\% & 104.03 & 38.53 & 27.13 & 8.07 & 18.99 \\
LSD 1\% & 240.24 & 88.97 & 62.64 & 18.63 & 43.85 \\
LSD 0.1\% & 764.52 & 283.13 & 199.35 & 59.30 & 139.53 \\
\hline Note: o/x significant negative/positive differences; oo/xx = distinctly significant negative/positive differences; ns = not significant &
\end{tabular}
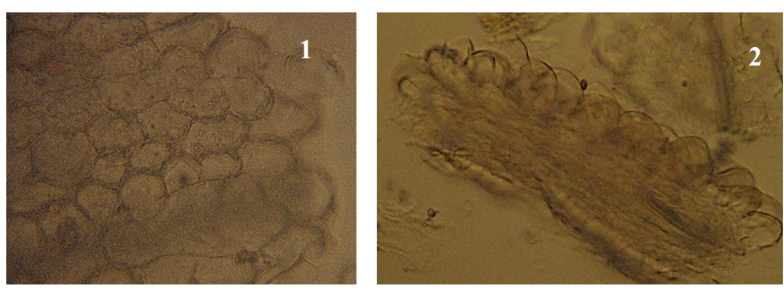

Fig. 2. Ligulate florets epidermis with papilla: (1) top view; (2) side view
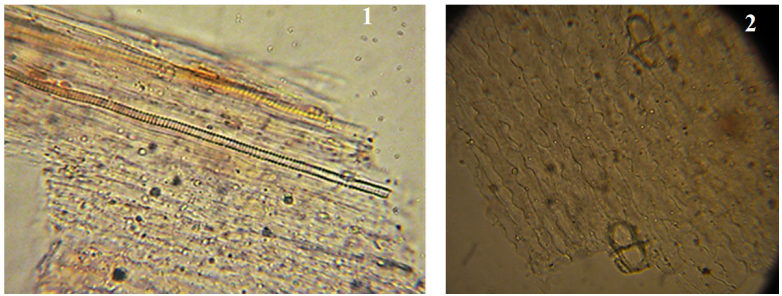

Fig. 3. Tubular florets epidermis: (1) general aspect with visible veins; (2) top view detail with biseriate glandular trichomes

application placement. Fertilizers with control-released nutrients (CRF) can meet the higher nutrient needs of Chrysanthemum better than water soluble fertilizers and also have a better impact on the yield and flowering characteristics (Zhu et al, 2009). As Asrar et al. (2014) mentioned, CRF prevent high salt accumulation in the growing media and reduce labour cost with positive environmental economic effects.

The morphological and yield parameters studied are shown in Tables 2 and 3 for both fertilised (V2) and nonfertilised (V1) treatments.

In chrysanthemum, nitrogen is essential for the production of biomass, the need for phosphorus is lower but potassium requirements are high, affecting growth and flower colouring (Liu $e t$ al., 2010; Kaplan et al., 2013). CRF does not affect height and width of plants at NPK tested ratio in local outdoor environment. These results are not in accordance with Sajid and Amin (2014) who reported increases in height with the application of $\mathrm{N}+\mathrm{P}+\mathrm{K}$, but in potted Chrysanthemum morifolium. The results could be explained by the higher rate of nutrient released quicker than estimated, in local alkaline soil at higher temperature of 2014 summer, as Basu et al. (2010) stated as possible.

As a statistical point of view, there are positive very significant differences for total number of branches per plant and these findings are correlated with positive distinctly significance on fresh and dry weight of plant. The data are in accordance with the findings of Sajid and Amin (2014), Ahmed et al. (2004). The total number of inflorescences and florets per plant was increased with CRF treatment. Plants treated had distinctly positive significance compared to the average. Similar results were reported by Sajid and Amin (2014), Asrar et al. (2014). Contrary to the cited studies, the diameter of inflorescences had distinctly negative significance in plants treated with CRF, while fresh and dry weights of inflorescences (flower head) were similar in both treatments.

Chrysanthemum indicum 'Avalon Red' is a late flowering cultivar and the data suggested that the use of a single dose of NPK 15-10-12, on the cultivation date, resulted in better growth of the plant architecture, significantly greater number of branches and inflorescences but does not ensure sufficient food material to produce increased flower size parameters in local outdoor soil and temperature conditions. The fresh weight of the flower head seems to be directly proportionate to the size of the inflorescences, in conformity with the findings of Javid et al. (2005) in Zinnia and Sajid and Amin (2014) in Chrysanthemum.

\section{Microscopic evaluation}

Most of the plants used in industry and in therapy are firstly identified by their microscopic features. Therefore, this research followed the general assessment procedure utilized for vegetal material that is intended to become a source for pharmaceutical industry. On a general aspect, there were no visible differences regarding the samples harvested from plants in different nutritional status, meaning that similar characteristics were noted for F1 and F2. Also, similarities were observed for leaves and stem samples, L1 and L2. The most significant elements identified are shown in Figs. 2, 3, 4,5 . 


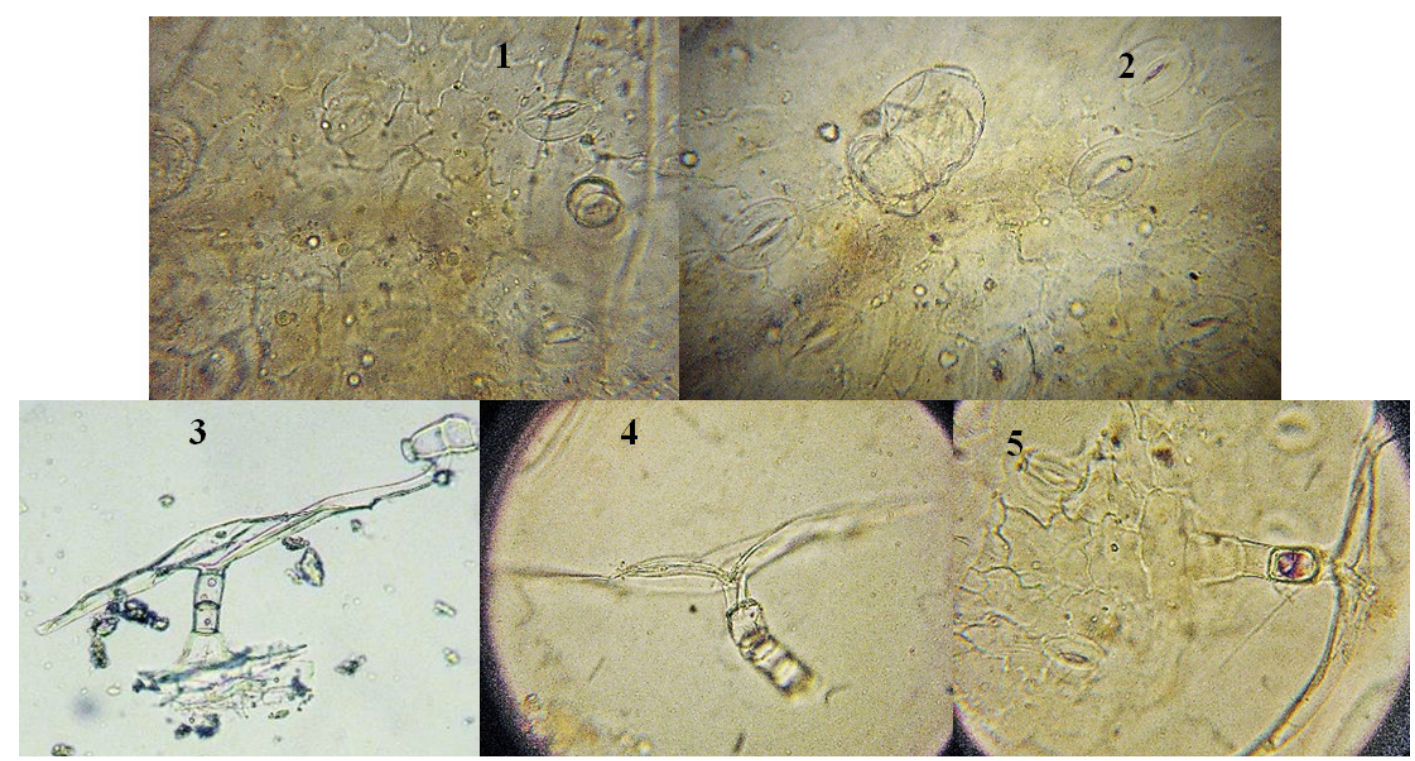

Fig. 4. The lower epidermis of the leaves: (1) general aspect with a surface hair viewed from top; (2) biseriate glandular trichome; $(3,4)$ T-shaped hairs side view; (5) nonglandular trichome attached to epidermis with stomata and visible pleated cuticle
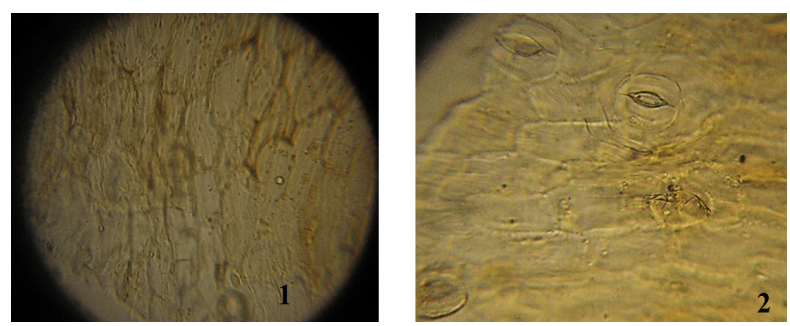

Fig. 5. Adaxial epidermis of the leaves: (1) general aspect with elongated polygonal cells and pleated cuticle; (2) top view detail

The flowers presented: fragments of the epidermis of ligulate florets composed of very thin-wall sinuous cells with large papilla (Fig. 2); fragments of the epidermis of tubular florets composed of elongated thin-wall sinuous cells with small druse and numerous biseriate glandular trichomes and thin group of reticulate conductor vessels (Fig. 3).

The leaves presented numerous surface T-shaped hairs, with a multicellular stalk (2-3 cells). The lower epidermis showed thin-wall very sinuous cells with stomata and rare biseriate glandular trichomes, whereas the upper epidermis fragments were composed of polygonal cells with a pleated cuticle. Morphological traits are illustrated in Figs. 4 and 5.

No significant differences were noted regarding the microscopic characteristics of variants. The biosynthetic capacity of plants could not be evaluated indirectly through microscopic traits.

\section{Identification of phenoliccompounds}

The general chemical profile was assessed in regards to some of the most common secondary metabolites found in Asteraceae species. The flavonoid and polyphenol acids spectrum was analysed by TLC means. The results showed that both Chrysanthermum indicum variants contain hyperoside, chlorogenic acid as well as other polyphenols in amounts that vary from one organ to another as indicated in the Fig. 6.

The chemical pattern of phenolic compounds and their concentration varied significantly in the aerial parts of

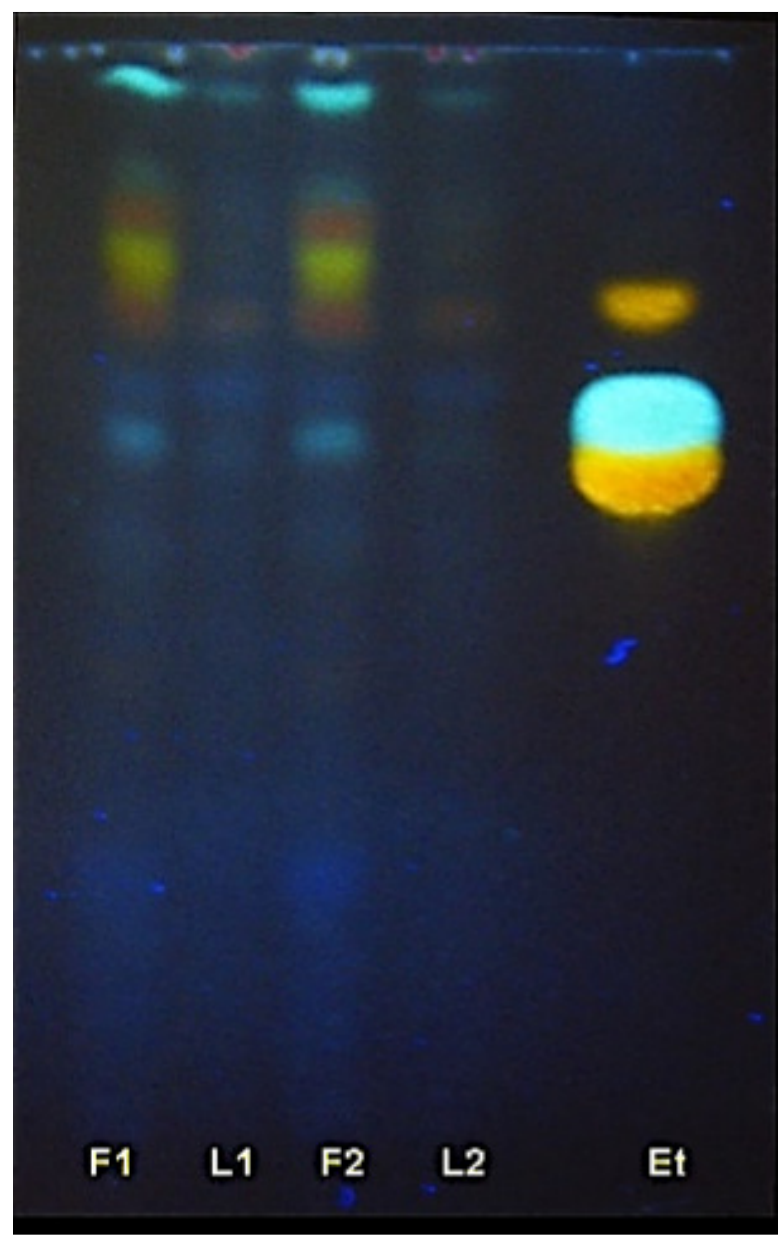

Fig. 6. TLC chromatogram for polyphenols examined in UV-365: F1/L1-inflorescences/leaves from unfertilized plants, F2/L2inflorescences/leaves from fertilized plants; Et- standards (in correct elution order): rutoside, chlorogenic acid, hyperoside 
376

Tabel 4.Total phenols in investigated Chrysanthemum samples

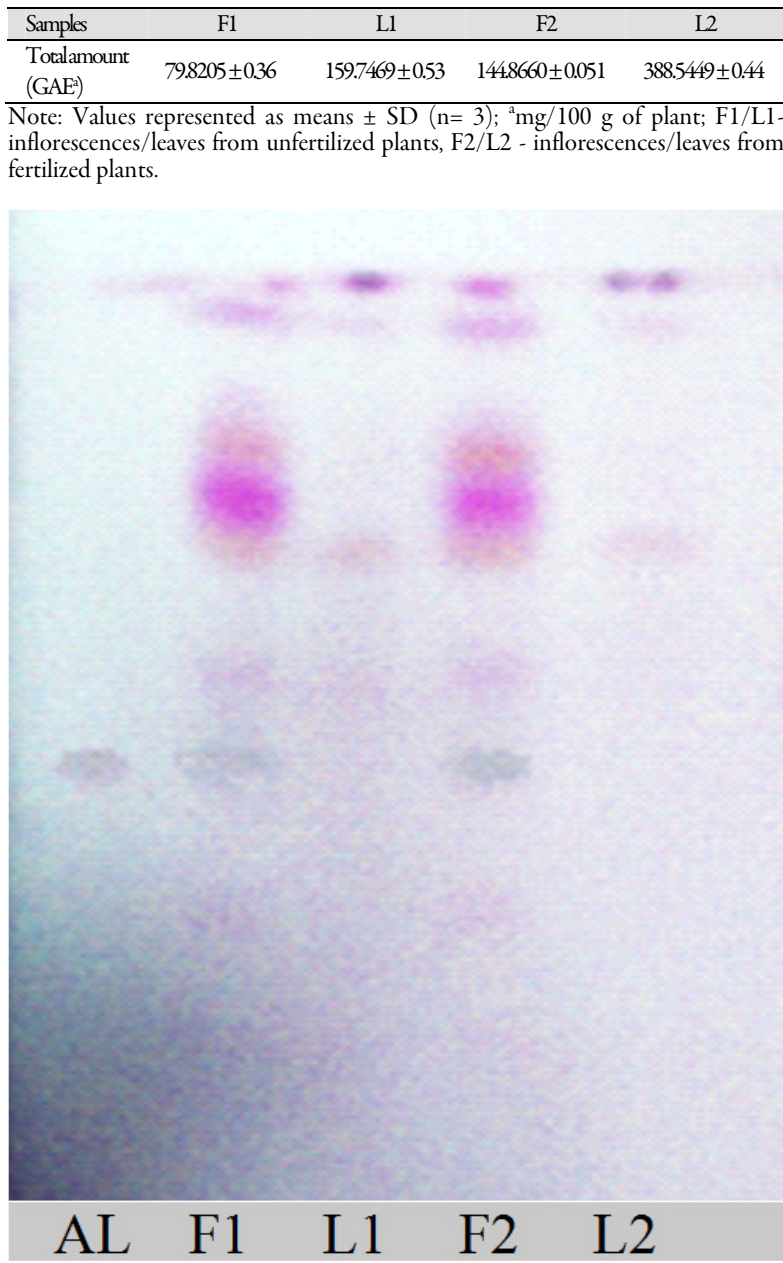

Fig. 7. TLC chromatogram for sesquiterpene lactones examined in VIS: samples F1/L1-inflorescences/leaves from unfertilized plants, F2/L2inflorescences/leaves from fertilized plants; standard: AL- alantolactone

chrysanthemum in different nutritional statuses. As indicated in the image, flavonoids show yellow to orange fluorescence, whereas polyphenol carboxylic acids formed blue fluorescence arias. Therefore, the samples contain four main polyphenol carboxylic acids (including chlorogenic acid) and three main flavonoids (hyperoside and other derivatives). Nevertheless, rutoside was not identified in our samples. According to TLC specialists (Wagner and Bladt, 2001) the blue fluorescence spot with $R_{f} 0.9$ can be attributed to caffeic acid, which would eluate a long path in the solvent system that we chose. Another conclusion that we draw from this TLC is that flowers are richest in studied compounds than the leaves samples.

\section{Totalpolyphenol content}

The phenolic content was evaluated to establish possible correlations between the nutritional status and the quantity of the chemical compounds. Recognised as natural antioxidants, both flavonoids and polyphenolic acid derivatives are used by plants for protection against $U V$ rays, for growth and also as insect attractants for pollination. Moreover, polyphenols biosynthesis in plants is enhances due to oxidative stress (Kumar and Pandey, 2013).
As it can be seen from Table 4 the amounts of phenols differ substantially between the samples. On a general note, flowers have half the quantity found in leaves for both nutritional statuses. Moreover, the plants biosynthetic capacity for polyphenols increases (doubles) with fertilisation. Although the TLC partially indicated the presence of such compounds in our samples, the elution system that was chosen allowed only certain groups to be evidenced. Therefore, it is highly probable that other phenolic compounds could be found in the leaves and stems of Chrysanthemum indicum 'Avalone Red'. The phenolic and flavonoid profile is in accordance with other authors, which stated that Chrysanthemum flower is a potent source of antioxidant compounds (Liang-Yuet al.,2010).

\section{Terpenoidpattern identification}

The terpenoids identification revealed that sesquiterpene lactones are present, while triterpenoids such as ursolic and oleanolic acids were absent. The TLC chromatogram for sesquiterpene lactones is presented in Fig. 7. The general overview indicated that alantolactone (violet grey zones) is present especially in flower samples, but there are other compounds (possibly helenalin methylated derivatives) that migrate in higher $\mathrm{R}_{\mathrm{f}}$ ranges (over 0.7). This is also visible in HPLC chromatogram.

\section{Identification and semiquantitative determination of the alantolactones}

The HPLC analysis confirmed the presence of alantolactone $(\mathrm{RT}=43.620 \pm 0.5 \%)$ as presented in the image from Fig. 8 .

Semiquantitative quantification showed that alantolactone found in samples is quite low (less than $0.1 \mathrm{mg} \%$ ), still leaves have much less than the flowers. Moreover, the fertilised samples contain only traces of alantolactone compared to the unfertilised samples.

The results indicated that alantolactone content is smaller in fertilised plants and flowers are richer than leaves and stems (together) in both variants, for studied metabolite. Phenolic content is greater in fertilised plants and the leaves in this variant have the highest content. Plants from V2 variant (fertilised) have a greater number of branches and inflorescences per plant that suggests that the level of alantolactone is negatively correlated with biomass, especially with ramification. These findings are in accordance with Supanjani et al. (2005) which have shown in Chrysanthemum coronarium plants that the decline in yield leads to greater accumulation in sesquiterpenlactones (SQL) in the flower heads. Also, Sulpice et al. (2009) pointed out that the level of the majority of plant metabolites is negatively correlated with biomass while Pljevljakušić et al. (2014) have found maximum sesquiterpene lactones levels in the samples of flower heads of Arnica montana poor developed variants. Ibrahim et al. (2011) have found greater accumulation of secondary metabolites in plants with affected $\mathrm{C} / \mathrm{N}$ ratio, which accumulate organic matter from photosynthesis in the form of secondary metabolites. It is also important to consider the effect of SQL on the plant in its natural environment, able to provide defense against microorganisms and insects (Chadwick et al., 2013). From this point of view, the alantolactone biosynthetic capacity of plants is greater in unfertilised plants, while the phenolic one is greater in fertilised plants in the present study.

Alantolactone represents a proven allergen and its presence in plants demonstrate that the plants are potentially allergenic. The tested cultivar, as other chrysanthemum varieties, could induce allergic contact dermatitis. TLC and HPLC profiles emphasized that there are also other sesquiterpenes lactones in plant extracts, possible allergenic. Other studies are needed to complete the terpenoid chemical profile of this ornamental. 


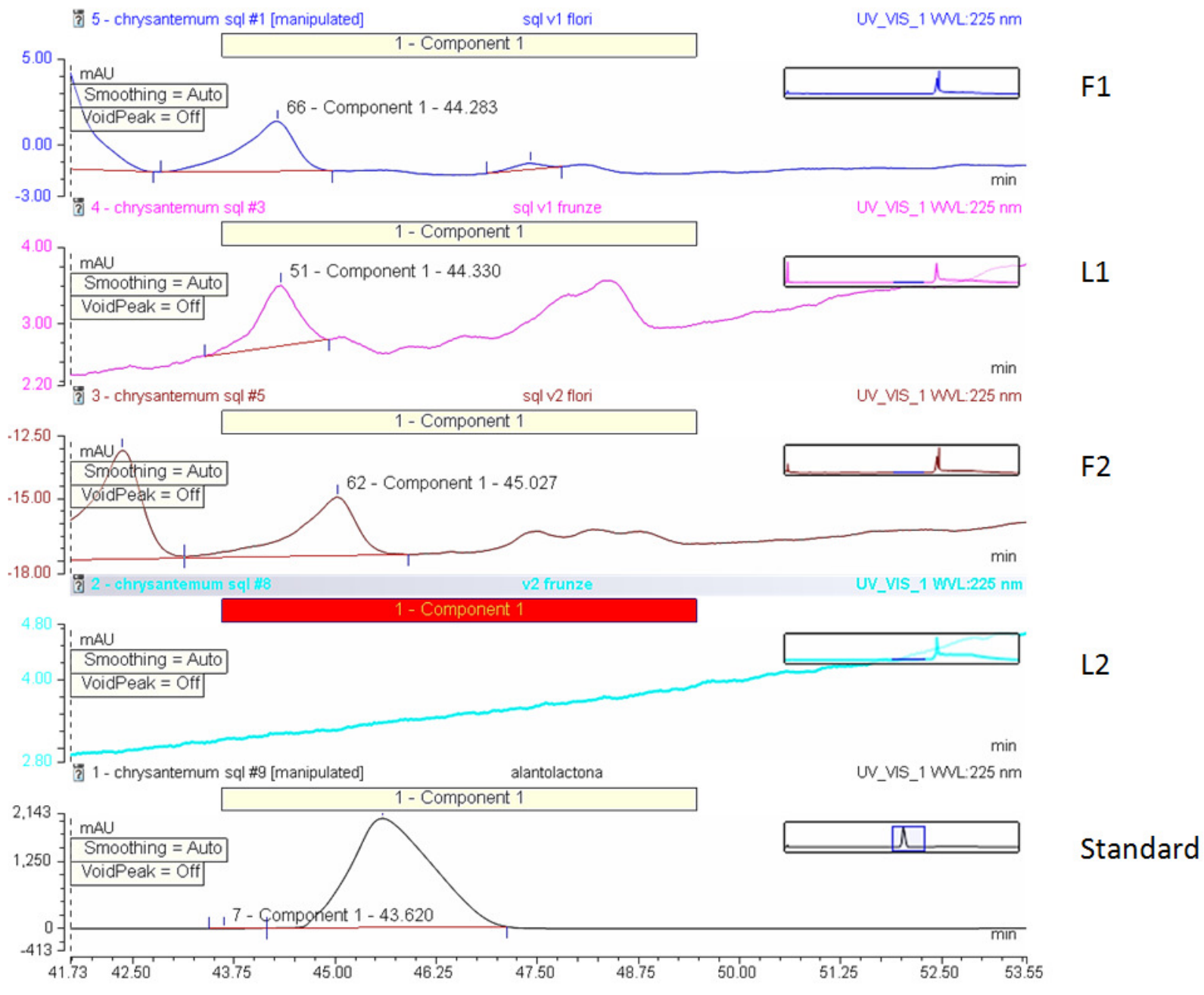

Fig. 8. HPLC identification of alantolactone from samples of Chrysanthemum indicum; F1/L1-inflorescences/leaves from unfertilized plants, F2/L2- inflorescences/leaves from fertilized plants

\section{Conclusion}

The morphology, hardiness and easy cultivation, with reduced labour cost make Chrysanthernum indicum cv. 'Avalone Red' an economically advantageous option both for growers and for employing it in landscape. Fertilisation intensifies the ramification of the plant and the growth of its biomass, increases the number of inflorescences but not their diameter. The qualitative chemical analyses confirmed the presence of flavonoids and of polyphenolcarboxilic acids, more so in flowers than in leaves. Total phenolic content is higher in leaves than in flowers. The fertilised plants have a higher phenolic content but smaller alantolactone content than unfertilised plants. Ursolic acid was not detected in the studied cultivar. The tested cultivar is a potent source of polyphenols, but alantolactone is present only in small quantities, as confirmed by the HPLC analysis. However, the presence of alantolactone alerts to the allergenic potential of plants and plant extracts, especially the extracts obtained from flowers. In addition to their use as ornamental plants, chrysanthemum can have a wide array of uses due to their bioactive compounds with antioxidant activity.

\section{Acknowledgement}

This work was supported by the European Social Fund, Human Resources Development Operational Programme 20072013, project no. POSDRU/159/1.5/S/132765.

\section{References}

Achika JI, Arthur DE, Gerald I, Adedayo A (2014). A review on the phytoconstituents and related medicinal properties of plants in the Asteraceae family. International Organization of Scientific Research Journal of Applied Chemistry 7(8):1-8.

Ahmed M, Khan MF, Hamid A, Hussain A (2004). Effect of urea, DAP and FYM on growth and flowering of Dahlia (Dablia variabilis). International Journal of Agriculture and Biology 6(2):393-395.

Ardelean M, Sestraş R, Cordea M (2007). Tehnică experimentală horticolă, [Horticultural experimental design]. Editura AcademicPres, ClujNapoca(in Romanian). 
Asrar AW, Elhindi K, Abdel-Salam E (2014). Growth and flowering response of chrysanthemum cultivars to Alar and slow-release fertilizer in an outdoor environment. Journal of Food, Agriculture and Environment 12(2):963-971.

Basu SK, Kumar N, Srivastava JP (2010). Modeling NPK release from spherically coated fertilizer granules. Simulation Modelling Practice and Theory 18:820-835.

Bessada SMF, Barreira JCM, Oliveira MB (2015). Asteraceae species with most prominent bioactivity and their potential applications: a review. Industrial Crops and Products 76:604-615.

Bi YF, Jia L, Shi SP, Sun XI, Chen YY, Zhang YB (2010). New sesquiterpenes from the flowers of Chrysanthemum indicum $\mathrm{L}$. Helvetica Chimica Acta 93:1953-1959.

Burzo I, Toma C (2013). Țesuturi secretoare şi substanțe volatile din plante [Secretory tissues and volatile substances from plants]. Editura Universitatii “Alexandru Ioan Cuza” (2nded), Iasi.

Buta E, Cantor M, Buta M (2011). The influence of phytosanitary treatments and fertilizers upon Chrysanthemum cultivars. Lucrari stiintificeUSAMV Iasi.Seria Horticultura 54:243-248.

Cantor M, Buta E (2010). Evaluation of biological potential and morphology in some cultivars of Chrysanthermum hortorum Bailey in solarium. Lucrari stiintifice USAMV Iasi. Seria Horticultura 53:247252.

Chadwick M, Trewin H, Gawthrop F, Wagstaff C (2013). Sesquiterpenoids lactones: Benefits to plant and people. International Journal of Molecular Science 14(6):12780-12805. doi:10.3390/ijms140612780.

Crosby DG (2004). The poisoned weed. Plants toxic to skin. Oxford University Press, New York.

Dai J, Mumper RJ (2010). Plant phenolics: extraction, analysis and their antioxidant properties (review). Molecules 15:7313-7352.

Debnath T, Jin HL, Hasnat A, Kim Y, Binte Samad N, Park PJ, Lim BO (2013). Antioxidant potential and oxidative DNA damage preventive activity of Chrysanthemum indicum extracts. Journal of Food Biochemistry 37(4):440-448.

Filippini R, Piovan A, Borsarini A, Caniato R (2010). Study of dynamic accumulation of secondary metabolites in three subspecies of Hypericum perforatum. Fitoterapia 81:115-119.

Fraga BM (2013). Natural sesquiterpenoids. Natural Product Reports 30:1226-1264.

Gould KS, Lister C (2006). Flavonoid function in plants. In: Andersen ØM, Marham KR (Eds). Flavonoids, chemistry, biochemistry and application. CRC Press, Boca Raton pp 397-442.

Habib AM, Zhagloul SM (2012). Effect of chemical, organic and biofertilization on growth and flowering of Chrysanthemum frutescens plants. Journal of Horticultural Science and Ornamental Plants 4(2):186-194.

Huang YP, Ling YR (1996). Economic compositae in China. In: Caligari PDS, Hind DJN (Eds). Compositae: biology and utilisation. Proceedings of the International Compositae 1994 Conference. Kew: Royal Botanic Gardens pp 431-451.

Ibrahim MH, Jaafar HZ, Rahmat A, Rahman ZA (2011). Effects of nitrogen fertilization on synthesis of primary and secondary metabolites in three varieties of kacip Fatimah (Labisia pumila Blume). International Journal of Molecular Sciences 12(8):52385254.

Jack AR, Norris PL, Storrs FJ (2013). Allergic contact dermatitis to plant extracts in cosmetics. Seminars in Cutaneous Medicine and Surgery 32:140-146.

Javid QA, Abbasi NA, Saleem N, Hafiz IA, Mughal AL (2005). Effect of NPK Fertilizer on Performance of Zinnia (Zinnia elegans) Wirlyging Shade. International Journal of Agriculture and Biology 7(3):471-473.

Kaplan L, Tlustoš P, Száková J, Najmanová J (2013). The influence of slow-release fertilizer on potted chrysanthemum growth and nutrient consumption. Plant, Soil and Environment 59(9):385391.

Kumar A, Singh SP, Bhakuni RS (2005). Secondary metabolites of Chrysanthemum genus and their biological activities. Current Science 89(9):1489-1501.

Kumar S, Pandey AK (2013). Chemistry and biological activities of flavonoids: an overview. The Scientific World Journal ID 162750.

Lattanzio V, Kroon PA, Quideau S, Treutter D (2008). Plant phenolics - secondary metabolites with diverse functions. In: Daayf F, Lattanzio V (Eds). Recent advances in polyphenol research, volume 1. Wiley-Blackwell, Oxford, UK doi:10.1002/9781444302400.ch1.

Lawal OA, Ogunwande IA, Olorunloba OF, Oloku AR (2014). The essential oils of Chrysanthemum morifolium Ramat from Nigeria. American Journal of Essential Oils and Natural Products 2(1):6366.

Li ZF, Wang ZD, Ji YY, Zhang S, Huang C, Li J, Xia XM (2009). Induction of apoptosis and cell cycle arrest in human HCC MHCC97H cells with Chrysanthemum indicum extract. World Journal of Gastroenterology 15(36):4538-46.

Liang-Yu W, Hong-Zhou G, Xun-Lei W, Jian-Hui Y, Jian-Liang L, Yul-Rong L (2010). Analysis of chemical composition of Chrysanthemum indicum flowers by GC/MS and HPLC. Journal of Medicinal Plant Research 4(5): 421-426.

Lim TK (2014). Edible Medicinal and Non-Medicinal Plants: Volume 7, Flowers. Springer Science \& Business Media, Dordrecht.

Liobikas J, Majiene D, Trumbeckaite S, Kursvietiene L, Masteikova R, Kopustinskiene DM, Savickas A, Bernatoniene J (2011). Uncoupling and antioxidant effects of ursolic acid in isolated rat heart mitochondria. Journal of Natural Products 74(7):1640-1644.

Liu W, Zhu DW, Liu DH, Geng MJ, Zhou WB, Mi WJ, Yang TW, Hamilton D (2010). Influence of nitrogen on the primary and secondary metabolism and synthesis of flavonoids in Chrysanthemum morifolium. Journal of Plant Nutrition 33:240254.

Lowell CR (1993). Plants and the skin. Blackwell Scientific, Oxford.

Niţă M, Toma C, Vidraşcu P (2001). Contributions to the knowledge of the morphology and anatomy of aerial vegetative organs from some Chrysanthemum varieties (Ch. indicum L.). Scientific Annals of "Alexandru Ioan Cuza" University of Iasi, New Series, Section IIa, Vegetal Biology 47:3-12.

Petrussa E, Braidot E, Zancani M, Peresson C, Bertolini A, Patui S, 
Vianello A (2013). Plant flavonoids - biosynthesis, transport and involvment in stress responses. International Journal of Molecular Sciences 14(7):14950-14973.

Pljevljakušić D, Janković T, Jelačić S, Novaković M, Menković N, Beatović D, Dajić-Stevanović Z (2014). Morphological and chemical characterization of Arnica montana L. under different cultivation models. Industrial Crops and Products 52:233-244.

Rasul A, Khan M, Ali M, Li J, Li X (2013). Targetting apoptosis pathways in cancer with alantolactone and isoalantolactone. The Scientific World Journal 248532.

Sajid M, Amin N (2014). Effect of various combinations of nitrogen, phosphorus and potash on enhancing the flowering time in Chrysanthemum (Chrysanthemum morifolium). International Journal of Biosciences 4(10):99-108.

Senthil S, Sridevi M, Pugalendi KV (2007). Protective effect of ursolic acid against myocardial ischemia induced by isoproterenol in rats. Toxicology Mechanisms and Methods 17(1):57-65.

Singleton VL, Rossi JA (1965). Colorimetry of total phenolics with phosphomolybdic-phosphotungstic acid reagents. American Journal of Enology and Viticulture 16:144-158.

Stampf JL, Benezra C, Klecak G, Geleick H, Schultz KH, Hausen B (1982). The sensitizing capacity of helenin and of two of its main constituents, the sesquiterpene lactone alantolactone and isoalantolactone: a comparison of epicutaneous and intradermal sensitizing methods in different strains of guinea pig. Contact Dermatitis 8(1):16-24.

Sulpice R, Pyl ET, Ishihara H, Trenkamp S, Steinfath M, Witucka-Wall $\mathrm{H}$, ... Stitt M (2009). Starch as a major integrator in the regulation of plant growth. In: Ecker JR (Ed). Proceedings of the National Academy of Sciences of the Unites States of America 106(25):10348-10353.

Supanjani ARMT, Yang MS, Han HS, Lee KD (2005). Role of calcium in yield and medicinal quality of Chrysanthemum coronarium $\mathrm{L}$. Journal of Agronomy 4:186-190.
Swierczyńska-Machura D, Krakovia KA, Palczynski C (2006). Occupational allergy caused by ornamental plants. Medycyna Pracy 57(4):359-364.

Tanaka T, Moriwaka S, Horio T (1987). Occupational dermatitis with simultaneous immediate and delayed allergy to Chrysanthemum. Contact Dermatitis 16:152-158.

Wagner H, Bladt S (2001). Plant drug analyses - a thin layer cromathography atlas. Springer (2nd ed), Berlin.

Wang ZD, Huang C, Li ZF, Yang J, Li BH, Liang RR, Dai ZJ, Liu ZW (2010). Chrysanthemum indicum ethanolic extract inhibits invasion of hepatocellular carcinoma via regulation of MMP/TIMP balance as therapeutic target. Oncology Reports 23(2):413-421.

Warshaw EM, Zug KA (1996). Sesquiterpene lactone allergy. American Journal of Contact Dermatitis 7:1-23.

Wickens GE (2001). Economic botany: Principles and practices. Springer Science \& Business Media, New York.

Wink M (2011). Occurrence and function of natural products. In: Pezzuto JM, Kato MJ (Eds). Phytochemistry and Pharmacognosy, Encyclopedia of Life Support Systems (EOLSS). Developed under the Auspices of the UNESCO, Eolss Publishers, Paris, France.

Yoshikawa M, Morikawa T, Murakami T, Toguchida I, Harima S, Matsuda H (1999). Medicinal flowers. I. Aldose reductase inhibitors and three new eudesmane-type sesquiterpenes, kikkanols A, B, and C, from the flowers of Chrysanthemum indicum L. Chemical and Pharmaceutical Bulletin 47(3):340-345.

Zheng ZL (2001). Modification of plant architecture in Chrysanthemum by ectopic expression of the tobacco phytochrome B1 gene. Journal of the American Society for Horticultural Science 126(1):19-26.

Zhu LX, WangJH, Sun YS, Li YP, Sun LW, Zhang CL (2009). Effects of two controlled-release fertilizers with different proportion of N, P and $\mathrm{K}$ on the nutrient uptake and growth of Chrysanthemum morifolium Ramat. Chinese Journal of Applied Ecology 20:16711677. 